\title{
MAPK and ERK polymorphisms are associated with PCOS risk in Chinese women
}

\author{
Lingmin Hu ${ }^{1, *}$, Yiting Zhang ${ }^{2, *}$, Li Chen ${ }^{1}$, Wei Zhou ${ }^{1}$, Yong Wang ${ }^{2}$ and Juan Wen ${ }^{3,4}$ \\ ${ }^{1}$ Department of Reproduction, The Affiliated Changzhou Maternity and Child Health Care Hospital of Nanjing Medical \\ University, Changzhou 213003, China \\ ${ }^{2}$ State Key Laboratory of Analytical Chemistry for Life Science, Jiangsu Key Laboratory of Molecular Medicine, Medical School \\ of Nanjing University, Nanjing 210093, China \\ ${ }^{3}$ Nanjing Maternity and Child Health Care Institute, Nanjing Maternity and Child Health Care Hospital, Obstetrics and \\ Gynecology Hospital Affiliated to Nanjing Medical University, Nanjing 210004, China \\ ${ }^{4}$ State Key Laboratory of Reproductive Medicine, Nanjing Maternity and Child Health Care Hospital, Obstetrics and Gynecology \\ Hospital Affiliated to Nanjing Medical University, Nanjing 210004, China \\ *These authors have contributed equally to this work
}

Correspondence to: Juan Wen, email:wenj2010@gmail.com

Keywords: variants; MAPK/ERK; RegulomeDB; polycystic ovarian syndrome

Received: June 03, $2017 \quad$ Accepted: October 02, 2017 Published: October 27, 2017

Copyright: $\mathrm{Hu}$ et al. This is an open-access article distributed under the terms of the Creative Commons Attribution License 3.0 (CC BY 3.0), which permits unrestricted use, distribution, and reproduction in any medium, provided the original author and source are credited.

\section{ABSTRACT}

In this case-control study, we analyzed the association between eight RegulomeDB-annotated single nucleotide polymorphisms (SNPs) in the MEK1, MEK2, ERK1 and ERK2 genes and polycystic ovarian syndrome (PCOS). Logistic regression analysis demonstrated that MEK1 rs12050732 (OR = 1.29 [95\%CI: 1.06-1.58], $P$ $=0.012), E R K 2$ rs2266966 (OR $=0.81[95 \% \mathrm{CI}: 0.67-0.99], P=0.040)$ and $E R K 2$ rs5999521 (OR $=0.66[95 \% \mathrm{CI}: 0.51-0.86], P=0.002)$ were associated with PCOS risk without adjusting for age and body mass index. Moreover, PCOS risk increased with allele dosage when these three polymorphisms were combined $\left(P_{\text {trend }}=0.001\right)$. These findings suggest that genetic variants in key MAPK and ERK genes contribute to PCOS risk in Chinese women.

\section{INTRODUCTION}

Polycystic ovarian syndrome (PCOS) is a common endocrine syndrome associated with oligo-ovulation or anovulation among women of reproductive age $[1,2]$. PCOS is characterized by elevated serum luteinizing hormone (LH) and testosterone (T) levels, although the serum follicle-stimulating hormone (FSH) levels are normal [3]. PCOS is also associated with increased risk for metabolic syndromes like insulin resistance, obesity and type 2 diabetes $[2,4,5]$. Both environmental and genetic factors contribute to the complex pathophysiology of PCOS. Candidate gene studies and genome-wide association studies (GWAS) have demonstrated that genetic components play an important role in PCOS susceptibility $[6,7]$.
MAPK/ERK signaling pathway includes mitogenactivated protein kinases (MAPKs), like extracellular signal-regulated kinases (ERKs), which integrate multiple biochemical and environmental signals through phosphorylation cascades. The MAPK/ERK signaling pathway regulates a wide variety of cellular processes such as proliferation, differentiation, transcriptional regulation and differentiation $[8,9]$. The upstream core MAPKs such as MEK1 and MEK2 phosphorylate and activate downstream effector kinases, ERK1 and ERK2 [10]. The MAPK/ERK signaling pathway is associated with steroid biosynthesis in ovarian granulosa cells [11, 12]. Aberrant MAPK/ERK signaling contributes to metabolic signaling defects and excessive ovarian androgen production in women with PCOS $[13,14]$. As the above, there is 
increasing evidence that MAPK/ERK pathway genes are associated with PCOS risk.

Functional annotation of GWAS data has shown that single nucleotide polymorphisms can be useful biomarkers for various human diseases $[15,16]$. RegulomeDB is a database that integrates regulatory information from ENCODE and other data sources and is a powerful tool that shows functional SNPs in specific chromosomal regions $[17,18]$. It has a scoring system from 1 to 6 for the annotated data on methylation, chromatin structure, protein motifs and binding. The lower score indicates high probability for a variant to be located in a functional region.

Several studies have used RegulomeDB to identify causal polymorphisms associated with human diseases such as lung cancer, colorectal cancer and so on [19-21]. In this case-control study, we analyzed PCOS risk with $M A P K / E R K$ gene polymorphisms that are annotated in RegulomeDB.

\section{RESULTS}

Table 1 shows clinical pathological characteristics of PCOS patients and controls in accordance with 2003 Rotterdam PCOS diagnose criteria. PCOS patients showed higher LH and T levels as well as body mass index (BMI) than control subjects.

Table 2 shows the genotypes distributions of the 8 SNPs (rs12050732, rs16949879 and rs4255740 in MEK1; rs9921806 in ERK1; rs3827303, rs5999521, rs2266966 and rs9610470 in ERK2) and their association with PCOS. These 8 SNPs showed low pairwise LD each other in cases and controls, respectively (Figure 1). The MEK1 rs12050732 SNP showed association with PCOS in the additive model for unadjusted data $(\mathrm{OR}=1.29$ (95\%CI: 1.06-1.58), $P=0.012)$. The ERK2 rs5999521 SNP showed association with PCOS in the additive model for unadjusted data $(\mathrm{OR}=0.81(95 \% \mathrm{CI}$ : 0.67-0.99), $P=0.040$ ). The ERK2 rs2266966 SNP showed association with PCOS in the additive model for unadjusted data $(\mathrm{OR}=0.66$ (95\%CI: $0.51-0.86), P$ $=0.002)$. In these all 3 polymorphisms, the data was insignificant when adjusted for age and BMI $(P>0.05)$. The ERK2 rs9610470 SNP did marginal association with $\mathrm{PCOS}$ in recessive model $(\mathrm{OR}=0.16$; $95 \% \mathrm{CI}$ : 0.02 $1.37 ; P=0.096)$. The remaining 4 SNPs (rs 16949879 and rs4255740 in MEK1; ERK1 rs9921806; rs3827303 in ERK2) showed no association with PCOS risk (Table 2).

We also assessed the cumulative effects of three SNPs (MEK1 rs12050732, ERK2 rs5999521 and ERK2 rs2266966) on PCOS risk (Table 3). We observed alleledosage association between the number of allele variants and PCOS risk in the additive model for unadjusted data $\left(P_{\text {trend }}=0.001\right)$ and marginal association when data was adjusted for age and BMI $(P$-value $=0.09)$. Individuals with 5-6 risk alleles showed higher risk for PCOS than those with $0-2$ risk alleles for unadjusted data $(\mathrm{OR}=1.23$ (95\% CI: $1.08-1.40), P=0.001)$. But, the correlation was not significant when the data was adjusted for age and BMI $(P=0.88)$. Furthermore, we observed no significant association between the three SNPs and PCOS risk in subgroups stratified by age $(\leq$ $30 \mathrm{y}$ and $>30 \mathrm{y})$ and BMI $\left(\leq 25 \mathrm{~kg} / \mathrm{m}^{2}\right.$ and $>25 \mathrm{~kg} / \mathrm{m}^{2}$; data not shown).

\section{DISCUSSION}

In this case-control study of Chinese individuals, we evaluated the association of genetic variants identified by RegulomeDB in MAPK/ERK genes with PCOS susceptibility. We found that MEK1 rs12050732, ERK2 rs2266966 and ERK2 rs5999521 were associated with PCOS risk.

The MAPK/ERK pathway plays an important role in the pathogenesis of PCOS. The phospho-ERK1/2 levels are reduced in PCOS granulosa cells [22], whereas the MAPK/ERK signaling pathway is hyperactive in the PCOS endometrium [23]. PCOS patients showed elevated serum T and LH levels [3]. In PCOS patients, MAPK signaling was activated by the LH receptor [24, 25]. Moreover, $T$ levels were elevated when patients were treated with the MAPK kinase inhibitor PD98059 [26, 27]. These data suggest that MAPK/ERK signaling regulates T and LH levels in PCOS patients [24-27].

MEK1 is located on human chromosome 15q22.31 and is a key gene in MAPK pathway [10]. LH consists of $\alpha$ and $\beta$ subunits, of which the $\beta$-subunit synthesis is the rate-limiting step in LH synthesis [28]. Overexpression of constitutively active MEK1 activates the LH $\beta$-subunit promoter [24]. MEK1 inhibitor U0126 blocks androgeninduced DNA synthesis, thereby demonstrating the role of MEK1 in androgen metabolism [29]. MEK1 rs12050732 is found in patients with esophageal carcinoma and gastric cancer [30]. MEK1 rs12050732 is a cis-eQTL for DIS3L, which has a RNA exosome subunit with endonucleolytic and 3'-5'exonucleolytic activity that degrades RNA [31].

ERK2 is located on chromosome 22q11.22 and is involved in many critical signal transduction pathways including LH signaling during ovulation [32, 33]. ERK2 deletion in mouse granulosa cells disrupts LHinduced meiotic progression in oocytes, ovulation, and luteinization [34]. ERK2 activation is critical for the normal feedback mechanism of insulin signaling and its aberrant activation contributes to insulin resistance in PCOS $[14,35]$. The RegulomeDB score of both the ERK2 SNPs, rs2266966 and rs5999521 was 2b, which indicated 
Table 1: Clinical pathological parameters in PCOS and control subjects

\begin{tabular}{lcccc}
\hline Parameters & Case & Control & T-test & \multicolumn{1}{c}{ P } \\
\hline Age & $27.36 \pm 5.27$ & $30.68 \pm 3.66$ & 9.030 & $<0.001$ \\
BMI & $22.84 \pm 3.74$ & $21.41 \pm 3.08$ & -5.200 & $<0.001$ \\
FSH (IU/L) & $6.41 \pm 2.67$ & $7.33 \pm 2.56$ & 4.266 & $<0.001$ \\
LH (IU/L) & $13.27 \pm 8.22$ & $5.10 \pm 3.36$ & -14.933 & $<0.001$ \\
E2 (pg/ml) & $66.94 \pm 48.52$ & $54.34 \pm 39.37$ & -3.347 & $<0.001$ \\
T $(\mathrm{ng} / \mathrm{ml})$ & $2.79 \pm 7.69$ & $1.09 \pm 1.01$ & -3.428 & $<0.001$ \\
\hline
\end{tabular}

BMI: body mass index; FSH: follicle-stimulating hormone; LH: luteinizing hormone; E2: estradiol; T: total testosterone.

Table 2: Association between $M E K$ and $E R K$ polymorphisms and PCOS risk

\begin{tabular}{|c|c|c|c|c|c|c|c|}
\hline SNP & Genotype & Case & Control & OR $(95 \% C I)$ & $P$ & OR $(95 \% C I)^{\mathrm{a}}$ & $P^{\mathrm{a}}$ \\
\hline \multirow{6}{*}{$\begin{array}{l}\text { MEK1 } \\
\text { rs12050732 }\end{array}$} & AA & 138 & 159 & 1.00 & 1.000 & 1.00 & 1.000 \\
\hline & CA & 188 & 196 & $1.11(0.82-1.50)$ & 0.518 & $1.06(0.73-1.56)$ & 0.753 \\
\hline & $\mathrm{CC}$ & 79 & 50 & $1.82(1.20-2.77)$ & $0.005^{b}$ & $1.54(0.89-2.66)$ & 0.124 \\
\hline & Dominant & & & $1.25(0.94-1.67)$ & 0.126 & $1.16(0.81-1.66)$ & 0.431 \\
\hline & Recessive & & & $1.72(1.17-2.53)$ & $0.006^{b}$ & $1.49(0.90-2.46)$ & 0.124 \\
\hline & Additive & & & $1.29(1.06-1.58)$ & $0.012^{b}$ & $1.19(0.92-1.55)$ & 0.179 \\
\hline \multirow[t]{6}{*}{$\begin{array}{l}\text { MEK1 } \\
\text { rs16949879 }\end{array}$} & AA & 140 & 142 & 1.00 & 1.000 & 1.00 & 1.000 \\
\hline & GA & 173 & 173 & $1.01(0.74-1.39)$ & 0.930 & $0.99(0.66-1.48)$ & 0.963 \\
\hline & GG & 75 & 68 & $1.12(0.75-1.67)$ & 0.585 & $1.31(0.79-2.19)$ & 0.293 \\
\hline & Dominant & & & $1.04(0.78-1.40)$ & 0.775 & $1.08(0.74-1.56)$ & 0.700 \\
\hline & Recessive & & & $1.11(0.77-1.60)$ & 0.574 & $1.32(0.84-2.09)$ & 0.233 \\
\hline & Additive & & & $1.05(0.86-1.28)$ & 0.621 & $1.12(0.87-1.44)$ & 0.366 \\
\hline \multirow[t]{6}{*}{$\begin{array}{l}M E K 1 \\
\text { rs } 4255740\end{array}$} & $\mathrm{CC}$ & 176 & 174 & 1.00 & 1.000 & 1.00 & 1.000 \\
\hline & $\mathrm{TC}$ & 189 & 188 & $0.99(0.74-1.33)$ & 0.967 & $1.01(0.70-1.47)$ & 0.953 \\
\hline & TT & 39 & 43 & $0.90(0.55-1.45)$ & 0.657 & $1.18(0.65-2.15)$ & 0.585 \\
\hline & $\begin{array}{l}\text { Dominant } \\
\text { Dominant }\end{array}$ & & & $0.98(0.74-1.29)$ & 0.863 & $1.04(0.73-1.48)$ & 0.824 \\
\hline & Recessive & & & $0.90(0.57-1.42)$ & 0.650 & $1.18(0.67-2.07)$ & 0.578 \\
\hline & Additive & & & $0.96(0.78-1.19)$ & 0.733 & $1.06(0.81-1.39)$ & 0.668 \\
\hline \multirow{6}{*}{$\begin{array}{l}\text { ERK1 } \\
\text { rs9921806 }\end{array}$} & $\mathrm{CC}$ & 261 & 282 & 1.00 & 1.000 & 1.00 & 1.000 \\
\hline & $\mathrm{TC}$ & 128 & 109 & $1.27(0.93-1.72)$ & 0.127 & $1.26(0.85-1.86)$ & 0.255 \\
\hline & TT & 13 & 14 & $1.00(0.46-2.17)$ & 0.993 & $2.37(0.84-6.67)$ & 0.103 \\
\hline & Dominant & & & $1.24(0.92-1.66)$ & 0.155 & $1.34(0.91-1.95)$ & 0.134 \\
\hline & Recessive & & & $0.93(0.43-2.01)$ & 0.860 & $2.22(0.79-6.21)$ & 0.129 \\
\hline & Additive & & & $1.16(0.90-1.50)$ & 0.244 & $1.35(0.97-1.88)$ & 0.074 \\
\hline $\begin{array}{l}E R K 2 \\
\text { rs3827303 }\end{array}$ & GG & 258 & 265 & 1.00 & 1.000 & 1.00 & $\begin{array}{c}1.000 \\
\text { (Continued) }\end{array}$ \\
\hline
\end{tabular}




\begin{tabular}{|c|c|c|c|c|c|c|c|}
\hline SNP & Genotype & Case & Control & OR (95\%CI) & $P$ & OR $(95 \% C I)^{a}$ & $P^{a}$ \\
\hline & $\mathrm{CG}$ & 132 & 121 & $1.12(0.83-1.51)$ & 0.458 & $1.07(0.73-1.58)$ & 0.737 \\
\hline & $\mathrm{CC}$ & 15 & 18 & $0.86(0.42-1.74)$ & 0.666 & $1.03(0.43-2.44)$ & 0.949 \\
\hline & Dominant & & & $1.09(0.81-1.45)$ & 0.574 & $1.06(0.73-1.54)$ & 0.745 \\
\hline & Recessive & & & $0.82(0.41-1.66)$ & 0.589 & $1.01(0.43-2.37)$ & 0.986 \\
\hline & Additive & & & $1.04(0.81-1.32)$ & 0.775 & $1.05(0.77-1.42)$ & 0.782 \\
\hline \multirow{6}{*}{$\begin{array}{l}E R K 2 \\
\text { rs5999521 }\end{array}$} & AA & 162 & 139 & 1.00 & 1.000 & 1.00 & 1.000 \\
\hline & GA & 183 & 185 & $0.85(0.63-1.15)$ & 0.292 & $1.10(0.74-1.63)$ & 0.638 \\
\hline & GG & 60 & 79 & $0.65(0.43-0.98)$ & $\mathbf{0 . 0 3 8}^{\mathrm{b}}$ & $0.72(0.43-1.20)$ & 0.203 \\
\hline & Dominant & & & $0.79(0.59-1.05)$ & 0.106 & $0.97(0.67-1.41)$ & 0.886 \\
\hline & Recessive & & & $0.71(0.49-1.03)$ & 0.072 & $0.68(0.43-1.08)$ & 0.103 \\
\hline & Additive & & & $0.81(0.67-0.99)$ & $0.040^{b}$ & $0.88(0.69-1.13)$ & 0.327 \\
\hline \multirow[t]{6}{*}{$\begin{array}{l}E R K 2 \\
\text { rs } 2266966\end{array}$} & TT & 279 & 241 & 1.00 & 1.000 & 1.00 & 1.000 \\
\hline & $\mathrm{CT}$ & 121 & 150 & $0.70(0.52-0.94)$ & $0.016^{b}$ & $0.92(0.63-1.33)$ & 0.643 \\
\hline & $\mathrm{CC}$ & 5 & 14 & $0.31(0.11-0.87)$ & $0.026^{b}$ & $0.33(0.09-1.14)$ & 0.079 \\
\hline & Dominant & & & $0.66(0.50-0.89)$ & $\mathbf{0 . 0 0 5}^{\mathrm{b}}$ & $0.86(0.60-1.23)$ & 0.408 \\
\hline & Recessive & & & $0.35(0.12-0.98)$ & $0.045^{b}$ & $0.34(0.10-1.17)$ & 0.086 \\
\hline & Additive & & & $0.66(0.51-0.86)$ & $0.002^{b}$ & $0.81(0.59-1.12)$ & 0.208 \\
\hline \multirow[t]{6}{*}{$\begin{array}{l}\text { ERK2 } \\
\text { rs9610470 }\end{array}$} & TT & 330 & 323 & 1.00 & 1.000 & 1.00 & 1.000 \\
\hline & CT & 74 & 76 & $0.95(0.67-1.36)$ & 0.791 & $1.22(0.79-1.9)$ & 0.372 \\
\hline & $\mathrm{CC}$ & 1 & 6 & $0.16(0.02-1.36)$ & 0.094 & $0.21(0.02-2.00)$ & 0.176 \\
\hline & Dominant & & & $0.90(0.63-1.27)$ & 0.534 & $1.13(0.73-1.74)$ & 0.578 \\
\hline & Recessive & & & $0.16(0.02-1.37)$ & 0.096 & $0.21(0.02-1.91)$ & 0.165 \\
\hline & Additive & & & $0.85(0.61-1.17)$ & 0.319 & $1.03(0.69-1.53)$ & 0.886 \\
\hline
\end{tabular}

${ }^{a}$ Adjusted for age and BMI. ${ }^{b}$ Significant parameters with $P<0.05$ are represented in bold.

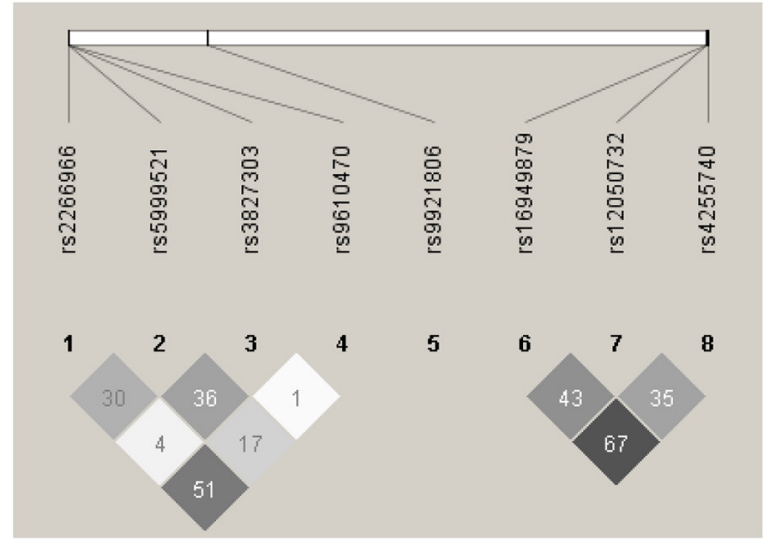

LD plot for cases.

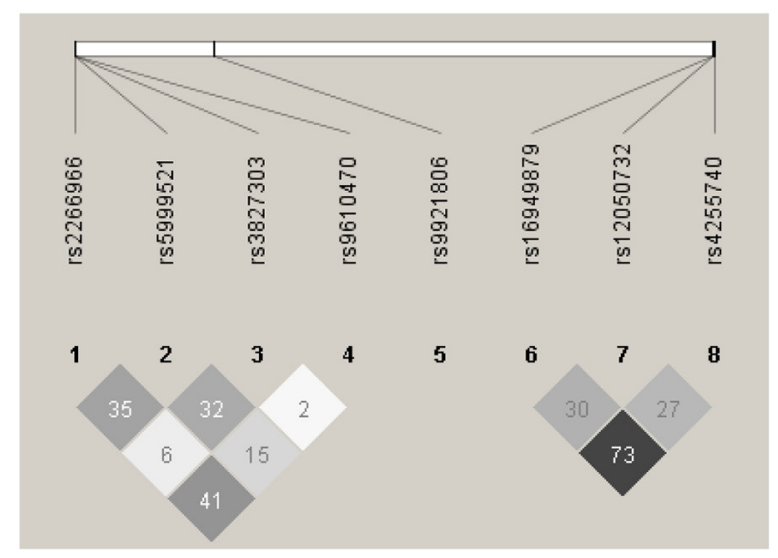

LD plot for controls.

Figure 1: Linkage disequilibrium (LD) based haploview $\mathbf{r}^{2}$ plot. 
Table 3: Association between combination of MEK1 rs12050732, ERK2 rs5999521 and ERK2 rs2266966 polymorphisms and PCOS risk

\begin{tabular}{lcccccc}
\hline No. of risk alleles & case & control & OR $\mathbf{( 9 5 \%}$ CI) & $\boldsymbol{P}$ & OR $(\mathbf{9 5 \%} \mathbf{C I})^{\mathbf{a}}$ & $\boldsymbol{P}^{\mathbf{a}}$ \\
\hline $0-2$ & 82 & 110 & 1 & 1 & 1 & 1 \\
3 & 73 & 91 & $1.08(0.71-1.64)$ & 0.73 & $1.38(0.83-2.30)$ & 0.22 \\
4 & 113 & 107 & $1.19(0.98-1.45)$ & 0.08 & $0.92(0.69-1.24)$ & 0.59 \\
$5-6$ & 137 & 98 & $1.23(1.08-1.40)$ & $\mathbf{0 . 0 0 1}^{\mathbf{b}}$ & $1.02(0.83-1.24)$ & 0.88 \\
Trend & & & $1.24(1.10-1.41)$ & $\mathbf{0 . 0 0 1}^{\mathbf{b}}$ & $1.14(0.98-1.33)$ & 0.09 \\
\hline
\end{tabular}

${ }^{\text {a }}$ Adjusted for age and BMI. ${ }^{\mathrm{b}}$ Significant parameters with $P<0.05$ are represented in bold.

binding to many proteins including transcription factors such as CTCF, IRF4, MYC, STAT2, and SP1 [36].

MEK2 is located on chromosome 19p13.3 and phosphorylates MAPK1/ERK2 and MAPK2/ERK3, thereby activating them [37]. RegulomeDB showed only one potentially functional variant of MEK2, which could not be genotyped. ERK1 is located on chromosome 16 p11.2 and translocates to the nucleus when activated by upstream kinases [37].

In summary, our study shows that multiple polymorphisms in MAPK/ERK genes are associated with PCOS risk in Chinese women. Further independent studies with large sample sizes are necessary to unravel the molecular mechanisms underlying this association and to further confirm our findings.

\section{MATERIALS AND METHODS}

\section{Study population}

This study was approved by the Human Research Ethics Committee of Changzhou Maternity and Child Health Care Hospital Affiliated to Nanjing Medical University. We recruited 405 PCOS and control subjects each for this study as described previously [38]. All the study subjects were Chinese women of Han ethnicity. They were recruited from the Department of Obstetrics and Gynecology of the Affiliated Hospital of Medical School of Nanjing University, the Centre of Reproduction Memorial Hospital of Sun Yat-Sen University, and the Department of Obstetrics and Gynecology of Anhui Medical University.

\section{PCOS diagnosis}

PCOS was diagnosed according to the revised 2003 consensus on diagnostic criteria and long-term health risks related to PCOS [39]. The criteria for PCOS diagnosis were as follows: (1) oligo ovulation and /or anovulation; (2) clinical and /or biochemical characterization of hyperandrogenism and (3) polycystic ovarian morphology based on ultrasound. At least 2 of the 3 criteria needed to be positive for the case to be classified as PCOS. Moreover, patients with diseases that cause hyperandrogenism such as congenital adrenal hyperplasia, hypothyroidism, Cushing's syndrome and androgensecreting tumors were excluded. The study subjects had not received hormone drugs or oral contraceptives three months prior to analysis. All subjects were interviewed face-to-face to collect demographic data and exposure information by trained interviewers. After signing informed consent, peripheral blood was collected during the $3^{\text {rd }}, 4^{\text {th }}$ and $5^{\text {th }}$ day of the menstrual cycle and at any time for those who had amenorrhea. Serum levels of FSH, LH, T and estradiol (E2) were measured by RIA assay (Beijing North Institute of Biological Technology of China and the CIS Company of France).

\section{Polymorphism genotyping}

We identified all polymorphisms in the MEK1, $M E K 2, E R K 1$ and ERK2 genes by Genome Reference Consortium Human Build 37 patch release 13 (GRCh37/ hg19) assembly. A lower RegulomeDB score indicated strong probability for a variant to be located in the functional region of a gene. Therefore, a polymorphism with a score of 1 probably affected transcription and expression of a target gene. We selected SNPs that were classified in the 1-2b category (http://regulome. stanford.edu). The selection criteria included minor allele frequency (MAF) $\geq 0.05$ and Hardy-Weinberg equilibrium $(\mathrm{HWE}) \geq 0.05$. Finally, SNPs with $\mathrm{R}^{2}$ values of pairwise linkage disequilibrium (LD) $<0.8$ were selected. The genomic DNA isolation method was as described previously [38]. Briefly, genomic DNA was isolated by proteinase $\mathrm{K}$ digestion and phenol chloroform extraction from leukocytes isolated from venous blood. Genotyping was performed by Sequenom's MassARRAY® iPLEX assay according to manufacturer's instructions without knowing the status of case and control. We included duplicate samples (5\%) for internal consistency and three water blanks as negative control in each reaction plate. 
Eight SNPs were successfully genotyped with call rate $>$ 95\% (Table 2).

\section{Statistical analysis}

We used $\chi^{2}$ test for categorical variables and Student's t-test for continuous variables to evaluate the differences between the cases and controls. HWE was evaluated using the goodness-of-fit $\chi^{2}$ test among controls. The association between genotypes and PCOS risk with or without adjustments for age and BMI was performed by calculating odds ratios (ORs) and their 95\% confidence intervals (CIs) from logistic regression analyses. The statistical analysis was conducted using SPSS Statistics Version 17.0 or PLINK (http://www.cog-genomics.org/ plink2/) software.

\section{Abbreviations}

MAP: mitogen-activated protein; PCOS: polycystic ovarian syndrome; SNPs: single nucleotide polymorphisms; BMI: body mass index; FSH: folliclestimulating hormone; LH: luteinizing hormone; E2: estradiol; T: total testosterone; GWAS: genome-wide association studies; MAPKs: MAP kinases; ERKs: extracellular signal-regulated kinases.

\section{Author contributions}

Lingmin $\mathrm{Hu}$ and Yiting Zhang performed experiments; Lingmin Hu and Juan Wen analyzed results and prepared figures; Lingmin $\mathrm{Hu}, \mathrm{Li}$ Chen and Wei Zhou designed the research and wrote the paper; Yong Wang and Juan Wen supervised the study.

\section{CONFLICTS OF INTEREST}

The authors declare that no conflicts of interest exist.

\section{FUNDING}

This study was supported by the Changzhou Natural Science Foundation (CJ20140021), National Natural Science Foundation of China (81402147, 81600685) Jiangsu Provincial Medical Youth Talent (QNRC2016304), the Natural Science Foundation of Jiangsu Province (BK20160141), and the Medical Science and technology development Foundation of Nanjing Department of Health (YKK16201).

\section{REFERENCES}

1. Franks S. Polycystic ovary syndrome. Arch Dis Child. 1997; 77:89-90.

2. Ehrmann DA. Polycystic ovary syndrome. N Engl J Med. 2005; 352:1223-1236.
3. Escobar-Morreale HF, Asuncion M, Calvo RM, Sancho J, San Millan JL. Receiver operating characteristic analysis of the performance of basal serum hormone profiles for the diagnosis of polycystic ovary syndrome in epidemiological studies. Eur J Endocrinol. 2001; 145:619-624.

4. Heutling D, Schulz H, Randeva H, Dodt C, Lehnert H. [Polycystic ovary syndrome. Prototype of a cardiometabolic syndrome]. [Article in German]. Internist (Berl). 2007; 48:144-153.

5. Klein J, Craven M, Vuguin PM. Polycystic ovarian syndrome. Adolesc Med State Art Rev. 2015; 26:326-342.

6. Chen ZJ, Zhao H, He L, Shi Y, Qin Y, Li Z, You L, Zhao J, Liu J, Liang X, Zhao X, Sun Y, Zhang B, et al. Genomewide association study identifies susceptibility loci for polycystic ovary syndrome on chromosome $2 \mathrm{p} 16.3,2 \mathrm{p} 21$ and 9q33.3. Nat Genet. 2011; 43:55-59.

7. Shi Y, Zhao H, Cao Y, Yang D, Li Z, Zhang B, Liang X, Li T, Chen J, Shen J, Zhao J, You L, Gao X, et al. Genome-wide association study identifies eight new risk loci for polycystic ovary syndrome. Nat Genet. 2012; 44:1020-1025.

8. Whitmarsh AJ, Davis RJ. Transcription factor AP-1 regulation by mitogen-activated protein kinase signal transduction pathways. J Mol Med (Berl). 1996; 74:589-607.

9. Vossler MR, Yao H, York RD, Pan MG, Rim CS, Stork PJ. cAMP activates MAP kinase and Elk-1 through a B-Rafand Rap1-dependent pathway. Cell. 1997; 89:73-82.

10. Peti W, Page R. Molecular basis of MAP kinase regulation. Protein Sci. 2013; 22:1698-1710.

11. Das S, Maizels ET, DeManno D, St Clair E, Adam SA, Hunzicker-Dunn M. A stimulatory role of cyclic adenosine 3', 5'-monophosphate in follicle-stimulating hormoneactivated mitogen-activated protein kinase signaling pathway in rat ovarian granulosa cells. Endocrinology. 1996; 137:967-974.

12. Tajima K, Dantes A, Yao Z, Sorokina K, Kotsuji F, Seger R, Amsterdam A. Down-regulation of steroidogenic response to gonadotropins in human and rat preovulatory granulosa cells involves mitogen-activated protein kinase activation and modulation of DAX-1 and steroidogenic factor-1. J Clin Endocrinol Metab. 2003; 88:2288-2299.

13. Nelson-Degrave VL, Wickenheisser JK, Hendricks KL, Asano T, Fujishiro M, Legro RS, Kimball SR, Strauss JF 3rd, McAllister JM. Alterations in mitogen-activated protein kinase kinase and extracellular regulated kinase signaling in theca cells contribute to excessive androgen production in polycystic ovary syndrome. Mol Endocrinol. 2005; 19:379-390.

14. Corbould A, Zhao H, Mirzoeva S, Aird F, Dunaif A. Enhanced mitogenic signaling in skeletal muscle of women with polycystic ovary syndrome. Diabetes. 2006; $55: 751-759$. 
15. Hong KW, Jeong SW, Chung M, Cho SB. Association between expression quantitative trait loci and metabolic traits in two Korean populations. PLoS One. 2014; 9:e114128.

16. Rajkumar AP, Christensen JH, Mattheisen M, Jacobsen I, Bache I, Pallesen J, Grove J, Qvist P, McQuillin A, Gurling HM, Tumer Z, Mors O, Borglum AD. Analysis of $\mathrm{t}(9 ; 17)$ (q33.2;q25.3) chromosomal breakpoint regions and genetic association reveals novel candidate genes for bipolar disorder. Bipolar Disord. 2015; 17:205-211.

17. ENCODE Project Consortium. An integrated encyclopedia of DNA elements in the human genome. Nature. 2012; 489:57-74.

18. Boyle AP, Hong EL, Hariharan M, Cheng Y, Schaub MA, Kasowski M, Karczewski KJ, Park J, Hitz BC, Weng S, Cherry JM, Snyder M. Annotation of functional variation in personal genomes using RegulomeDB. Genome Res. 2012; 22:1790-1797.

19. Lou J, Gong J, Ke J, Tian J, Zhang Y, Li J, Yang Y, Zhu Y, Gong Y, Li L, Chang J, Zhong R, Miao X. A functional polymorphism located at transcription factor binding sites, rs6695837 near LAMC1 gene, confers risk of colorectal cancer in Chinese populations. Carcinogenesis. 2017; 38:177-183.

20. Zhao J, Akinsanmi I, Arafat D, Cradick TJ, Lee CM, Banskota S, Marigorta UM, Bao G, Gibson G. A burden of rare variants associated with extremes of gene expression in human peripheral blood. Am J Hum Genet. 2016; 98:299-309.

21. Lee SY, Hong MJ, Jeon HS, Choi YY, Choi JE, Kang HG, Jung DK, Jin C, Do SK, Yoo SS, Seok Y, Lee EB, Shin $\mathrm{KM}$, et al. Functional intronic ERCC1 polymorphism from regulomeDB can predict survival in lung cancer after surgery. Oncotarget. 2015; 6:24522-24532. https://doi. org/10.18632/oncotarget.4083.

22. Lan CW, Chen MJ, Tai KY, Yu DC, Yang YC, Jan PS, Yang YS, Chen HF, Ho HN. Functional microarray analysis of differentially expressed genes in granulosa cells from women with polycystic ovary syndrome related to MAPK/ ERK signaling. Sci Rep. 2015; 5:14994.

23. Song XR, Zhang HY, Zhang YF, Han YK, Li KJ. [Extracellular signal-regulated protein kinase activation in endometrium with polycystic ovary syndrome and its significance]. [Article in Chinese]. Zhonghua Fu Chan Ke Za Zhi. 2010; 45:767-771.

24. Yamada Y, Yamamoto $H$, Yonehara $T$, Kanasaki $H$, Nakanishi H, Miyamoto E, Miyazaki K. Differential activation of the luteinizing hormone beta-subunit promoter by activin and gonadotropin-releasing hormone: a role for the mitogen-activated protein kinase signaling pathway in LbetaT2 gonadotrophs. Biol Reprod. 2004; 70:236-243.

25. Sun C, He M, Ko WK, Wong AO. Mechanisms for luteinizing hormone induction of growth hormone gene transcription in fish model: crosstalk of the cAMP/PKA pathway with MAPK-and PI3K-dependent cascades. Mol Cell Endocrinol. 2014; 382:835-850.

26. Patel SS, Beshay VE, Escobar JC, Suzuki T, Carr BR. Molecular mechanism for repression of 17alphahydroxylase expression and androstenedione production in granulosa cells. J Clin Endocrinol Metab. 2009; 94:5163-5168.

27. Ye DF, Ma HX, Mu WT, Lai MH, Liu H, Zheng YH, Ma WY. [Effective Ingredients of Yangjing Zhongyu Decoction Regulated Androgen Biosyntheses by Mitogen-Activated Protein Kinase Pathway in Porcine Granulose Cells]. [Article in Chinese]. Zhongguo Zhong Xi Yi Jie He Za Zhi. 2015; 35:847-853.

28. Matzuk MM, Spangler MM, Camel M, Suganuma N, Boime I. Mutagenesis and chimeric genes define determinants in the beta subunits of human chorionic gonadotropin and lutropin for secretion and assembly. J Cell Biol. 1989; 109:1429-1438.

29. Katayama H, Murashima T, Saeki Y, Nishizawa Y. The pure anti-androgen bicalutamide inhibits cyclin A expression both in androgen-dependent and -independent cell lines. Int J Oncol. 2010; 36:553-562.

30. Li WQ, Hu N, Wang Z, Yu K, Su H, Wang L, Wang C, Chanock SJ, Burdett L, Ding T, Qiao YL, Fan JH, Wang Y, et al. Genetic variants in epidermal growth factor receptor pathway genes and risk of esophageal squamous cell carcinoma and gastric cancer in a Chinese population. PLoS One. 2013; 8:e68999.

31. Tomecki R, Kristiansen MS, Lykke-Andersen S, Chlebowski A, Larsen KM, Szczesny RJ, Drazkowska K, Pastula A, Andersen JS, Stepien PP, Dziembowski A, Jensen $\mathrm{TH}$. The human core exosome interacts with differentially localized processive RNases: hDIS3 and hDIS3L. EMBO J. 2010; 29:2342-2357.

32. Siddappa D, Beaulieu E, Gevry N, Roux PP, Bordignon V, Duggavathi R. Effect of the transient pharmacological inhibition of Mapk3/1 pathway on ovulation in mice. PLoS One. 2015; 10:e0119387.

33. Prochazka R, Blaha M. Regulation of mitogen-activated protein kinase $3 / 1$ activity during meiosis resumption in mammals. J Reprod Dev. 2015; 61:495-502.

34. Fan HY, Liu Z, Shimada M, Sterneck E, Johnson PF, Hedrick SM, Richards JS. MAPK3/1 (ERK1/2) in ovarian granulosa cells are essential for female fertility. Science. 2009; 324:938-941.

35. Corbould A, Kim YB, Youngren JF, Pender C, Kahn BB, Lee A, Dunaif A. Insulin resistance in the skeletal muscle of women with PCOS involves intrinsic and acquired defects in insulin signaling. Am J Physiol Endocrinol Metab. 2005; 288:E1047-1054.

36. Anjali G, Kaur S, Lakra R, Taneja J, Kalsey GS, Nagendra A, Shrivastav TG, Devi MG, Malhotra N, Kriplani A, Singh R. FSH stimulates IRS-2 expression in human granulosa 
cells through cAMP/SP1, an inoperative FSH action in PCOS patients. Cell Signal. 2015; 27:2452-2466.

37. Guan KL. The mitogen activated protein kinase signal transduction pathway: from the cell surface to the nucleus. Cell Signal. 1994; 6:581-589.

38. Zhang CW, Zhang XL, Xia YJ, Cao YX, Wang WJ, Xu P, Che YN, Wu XK, Yi L, Gao Q, Wang Y. Association between polymorphisms of the CYP11A1 gene and polycystic ovary syndrome in Chinese women. Mol Biol Rep. 2012; 39:8379-8385.

39. Rotterdam ESHRE/ASRM-Sponsored PCOS consensus workshop group. Revised 2003 consensus on diagnostic criteria and long-term health risks related to polycystic ovary syndrome (PCOS). Hum Reprod. 2004; 19:41-47. 